\title{
ADULT JOKES IN SAUSAGE PARTY MOVIE: A STUDY OF MULTIMODALITY
}

\author{
a'Muhammad Wahyu Firmansyah, bisetyo Ariyanti \\ Universitas Negeri Surabaya, Indonesia \\ e-mail:muhammad.17020154003@mhs.unesa.ac.id
}

\begin{abstract}
The Sausage Party Movie is a comedy film directed by Conrad Vernon and Greg Tiernan (2016) which is sensational. The theme brings some controversy among people about how vulgar it is. The story exposed some sensitive themes such as intercourse, orgy, homosexuality, bisexuality, foreplay, torturing, murderer, annihilation, genocide, colonial domination, and other aspects as well. The contested scenes in the movie which manifest adult jokes are being analyzed by investigating the visual and linguistic elements related to the particular scenes. Thus, this study analyzed the adult jokes in "Sausage Party" by using multimodality approach which combines types of metafunction from Systemic Functional Linguistic (SFL) and visual elements of Gunther Kress and Theo van Leeuwen framework. The data were all scenes which contain adult jokes in this movie. The result reveals that some scenes may construct the meaning which related with the adult jokes. Despite the fact that this film is a comedy cartoon which associated with children, many adult jokes are being displayed to entertain the audiences which not suitable for underage communities. Likewise, the adult jokes are displayed as implicitly as possible to entertain either the underage who thinks it is only a usual joke or the adulthood who socially and practically understood the meaning behind it. In addition, the data is occupied by an intercourse activity between sausage and bun, torturing and murdered ideas, and also the idea of how human had intercourse from another perspective.
\end{abstract}

Keywords: Adult Jokes, Movie Analysis, Multimodality. 


\section{BACKGROUND}

Nowadays, humor or joke language has a high profile in our society (Ross, 2005), since almost all of the people enjoy and adore this kind of language. This language can be delivered by some media such as stand-up comedy and comedy movie, also by humorous advertisement and even in comic strips of newspaper (Nita, 2015). Thus, comedy movie is one of the movie genres that give people with high frequency of humorous content, either by visual or non-visual elements. In fact, animated cartoons convey its messages via their humorous representation and comment of the reality (Tsakona, 2009). However, nowadays animated children's film started to change its focus. Because of the business, they need to produce a product that sells (Chelsie, 2013). Many film industries changed to conclude the adults as their main audience. The main transforms that can be acknowledged by viewers in animated children's films is the increasing of adult joke in animated cartoon. One of the examples is Sausage Party Movie, a 2016 animated comedy by Sony Pictures. It is quite an offensive one, even though it is categorized as a comedy film. Overall, some adult jokes are displayed implicitly to entertain the audiences from the adult side only which are about death and religion, but it not too much rather than the sex jokes (Ross, 2005).

Therefore, language is a social semiotic aspect that refers to a system for making some meanings (Nugraha \& Mahdi, 2020). Thus, any language is can be used in any text and it reflects the knowledge of the members from some communities since literature and language are the product of culture which has its function in relation to social environment and reality that portrayed in literary works (Wahyuni, 2014). One of them is adult joke, based on the name, obviously this kind of joke is for adulthood, in other word, it is not suitable for children or underage communities to see, watch, or even listen (Heljakka, 2016). From this perspective, age is socially constructed on the basic knowledge of the discourse (Chivanec \& Ermida, 2012). Therefore, it can be argued that adult joke is directed to adulthood only because they socially and practically understand the meaning behind this joke. Then, adult joke may contain about death or murdered idea, religion or ideology, politics affair, and even sex jokes since all of them are a taboo concept in the most of culture (Chelsie, 2013; Ross, 2005). Despite of that, nowadays, many works are also depicted this kind of jokes without concerning the others communities. It is true that any works are expected as the human expression, in term of how people express their experiences, feelings, and imaginations, which resembles the reality of life. However, the film industries try to put this joke implicitly to their works, just to be enjoyable for children and also attract the adulthood at the same time. Thus, multimodality is a potential framework for making meaning since this linguistic aspect is an approach to understand the communication and representation of signs in language (Bo, 2018).

Multimodal discourse analysis is approaching the meaning through the use of language and visual imagery in the works (O'Halloran, 2008). Then, it will be involving the linguistic elements and visual forms as well. Thus, multimodality is a study of how multiple communication modes to combine and make some meaning ( $\mathrm{S}$. Knox, 2012). In fact, multimodality is used to analyzing and understanding visual displays and the connection between a verbal and visual element in media discourses (Chasanah, 2020).

Thus, in order to make a meaning, the essential of metafunctions are needed. According to Halliday (1989), there are three metafunctions of language, Ideational function, Interpersonal function and Textual function. Therefore, the ideational 
function uses language to represent experience (Butt \& Fahey, 2000) or representing the real world as it apprehended in real experience (Halliday \& Hasan, 1989). Then, it can be assumed that this metafunction is to convey the expression of some processes, events and actions at the real world. Ideational function is regarded by the existence of 'PARTICIPANT', 'PROCESS' and 'CIRCUMSTANCE' (Butt \& Fahey, 2000). Then, the types of 'PROCESSES' are material process, verbal process, behavioral process, relational process, mental process and existential process (Butt \& Fahey, 2000; Nugraha \& Mahdi, 2020). Interpersonal function uses language to encode the interaction (Butt \& Fahey, 2000), or the language is a piece of interaction between speaker and listener (Halliday \& Hasan, 1989). It uses to enable people to participate in communication and express their own feeling and attitude. This metafucntion represented by SUBJECT, FINITE, PREDICATOR, COMPLEMENT, and Mood Block, Residue, also Mood tag (Butt \& Fahey, 2000). Then, textual function uses language to organize the other metafunction into a coherent work (Butt \& Fahey, 2000). It can be referred to the fact that language has a way to turn a random list of sentences into a coherent passage (Halliday \& Hasan, 1989; Liu, 2019). Therefore, in textual function, language is used to relate what is said or written by the other metafunction as well. It represented by THEME and RHEME (Butt \& Fahey, 2000).

Furthermore, for the visual elements, this study adopted the idea of Gunther Kress and Theo van Leeuwen framework (2006) about visual resources. There are many resources that can be used such as visual images, space, and even architecture (O'Halloran, 2004). Further, some simple aspects such as position of the actor, color of the background, size of the frame, and angel have their own way to determine the meaning behind the image (Gunther \& Leeuwen, 2006). Also, visual sense includes such as color, image, light, body movement and facial expression; auditory sense falls into language, music and sound (Bo, 2018). Thus, all of those attributes proved the meaning for the audience as well.

Studies on multimodal analysis have been done by previous studies such as Liu (2019), Savitri \& Rosa (2019), and Bo (2018). In addition, those studies represent as the basic studies for this paper. The first study of using multimodal discourse analysis in Public Service Advertisement, a study conducted by Liu (2019). This study is focused on the Interactive meaning by Kress's perspective as Interpersonal metafunction from SFL and the goal of this study is to analyze how the multimodal discourses of Public Service Advertisement (PSA) interact and exert the effects. Then, the second is study on analyzing multimodal in Samsung Galaxy 09 audiovisual advertisement by Savitri and Rosa (2019). The study focused on the analyzed from discourse analysis perspective which is the multimodal system based on Kress and Leeuwen's multimodal theory, Halliday's systemic functional linguistics and Cheong's generis structure analysis. The study shows that there are five generic structures founded in the advertisement, they are announcement, display, video, emblem, lead, call and visit. There is also a study which focused to analyze the Movie Argo by Bo (2018). This study is based on the multimodal discourse theory, its analysis of some scenes in the movie Argo from the perspective of context of situation and culture also the meaning of image. It revealed that this movie constructs multimodal discourse through image and language, and successfully spreads western mainstream ideology.

Then, those previous study has some similarities regarding the present study. The pattern is similar which focused on the multimodal analysis. However, unlike those previous study, in this study, metafunction of Systemic Functional Language 
(SFL) by Halliday (1989) is applied together with the visual element by Gunther \& Leeuwen (2006) in some particular joke which adult joke only. Thus, the purpose of this study is to analyze the Sasuage Party Movie's adult jokes using multimodal discourse analysis framework, based on Halliday's Metafunction in SFL and Kress \& Leewuen visual design.

\section{RESEARCH METHODS}

In accordance with the purpose of the study related to analyzing the adult jokes in Sausage Party Movie using multimodality approach, the study applied descriptive qualitative research design since it depicts in detail of some certain phenomena through analysis and conveys the results properly in the form of detail explanation (Creswell, 2014).

The data was three scenes taken from the movie entitled Sausage Party Movie (2016). Elements in the scene such as image, colour, position, angle, size of frame were chosen to be analyzed in term of their visual elements by Kress and Leeuwen (2006), and the dialogue of the characters in the terms of linguistic elements by Halliday (1989). Then, the data were collected through documentation method by taking particular scenes to be analyzed and in the form of image by screenshot it.

In the process of data analysis, there were some steps conducted. The first step was watching through the whole movie. The second step was capturing some particular scenes and writing down the transcript of the dialogue regarding the adult joke. In the third step, all elements either visual and linguistic were sorted synchronously. The last, analyzing all of the elements by using Halliday SFL Theory and Kress \& Theo van Leeuwen framework to conduct the meaning of the joke.

\section{DISCUSSION}

From the movie, the study finds 3 scenes which will be analyzed respectively in order to inquire how various modalities work together. Therefore, from those scenes, 3 dialogues are categorized expressing material process based on Halliday's SFL Theory (1989) which depict the physical activity toward the goal of the passage and by using Gunther Kress and Theo van Leeuwen (2006) to identify the visual elements which displayed on the scenes such as position, colour, brightness and so on. Thus, the first scene is about the intercourse activity between non-living creature, the second is about torturing and murdered ideas, and the last is the idea of how human had intercourse from another perspective.

Therefore, the first scene was taken on 04:42 - 04:44 which focused on the dialogue of Frank while celebrates the coming of Red, White, and Blue day. He said, "We are gonna be 5 inches deep in some bun" to his comrades while showing a cheerful expression. Therefore, the analyzed of this scene is described below:

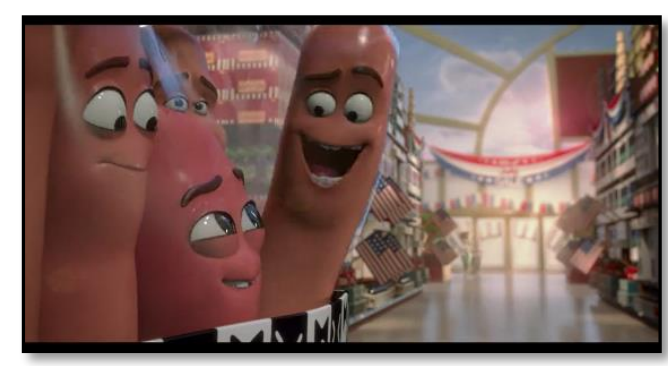

Figure 1 : First Scene 
From Figure 1, it shows the scene where focused on the conversation of the sausages. The background is dominated by the lightness theme which is possibility representing the purity value of the scene (Gunther \& Leeuwen, 2006). Then, the scene is used the close-up frame which showed the head and shoulder of the character, this scene intends to tell the audiences to more focused on the sausages than the rest items in this scene. Therefore, the position of characters are located on the left side which indicates the sign of 'already given' or it assumed to be already known by the audiences what are the characters' form (Gunther \& Leeuwen, 2006). Then, the blurring on the right side is representing the boundaries between static objects and dynamic objects of the left side (Gunther \& Leeuwen, 2006).

Table 1. Dialogue in The First Scene

\begin{tabular}{c|c|c|c|c}
\hline \multicolumn{1}{c}{ “We } & \multicolumn{1}{c}{ are } & gonna be & 5 inches deep & in some bun.” \\
\hline Actor & \multicolumn{2}{c}{ Process:Material } & Circumtances & Goal \\
\hline Subject & $\begin{array}{c}\text { Finite }+ \\
\text { (Present) }\end{array}$ & Predicator & Adjunct & Complement \\
\hline \multicolumn{2}{c|}{ Mood Block } & \multicolumn{3}{c}{ Residue } \\
\hline Theme & \multicolumn{2}{c}{ Rheme } \\
\hline
\end{tabular}

From Table-1, there are two participants which is we as the actor and some bun is labeled as the goal of the process, because it is the participant who is concerning by the actor with the action of are gonna be which depict physical activities by the actor. Then, it can be interpreted that Frank is representing himself and other sausages by used we, as the actor of the process. Therefore, this sentence intends to tell that Frank and other sausages are going to do physical activity; to be precisely is 5 inches deep in some bun on the Red, White, and Blue day. Then, the other metafunction, based on the interpersonal function, this sentence defines as giving an information to the receiver and categorized as the declarative mood because the subject is preceding the finite. Then, the finite are is a sign of time in relation to the speaker and resembling the event is presently occurring and + symbol is resembling the positive polarity of the speaker. Then, based on the textual function, this sentence is categorized as topical theme because it begins with the subject of $w e$. Therefore, it indicates that the focus of this sentence is to inform about Frank's intention and the sausages which represented by we.

Therefore, those elements are cooperating to construct some meaning in this scene. To begin with, this scene is giving an information that Frank and his friends are gonna be 5 inches deep in some bun on Red, Blue, White day which referred by we as the actor. Frank gives an information to Barry about him and his comrades' physical activity toward some bun. Then, this scene is focused on the conversation of sausage on the left side which assumed that everyone is already know about this information and also the boundaries between the static and dynamic which made the sausages are more important than anything on this scene. In fact, a word or phrase may have a double meaning and when a particular object has a sexual connotation such as wiener or sausage, it can be enough to trigger the jokes to be laughable (Ross, 2005). Meanwhile, in the real world, there is a food which named as 'Hot Dog' and this is what they are going to be in later. However, the fact that all of the things here are alive and had a soul in their self is the main case. It depicted in their mind that they are not going to become a usual 'Hot Dog', because the sausage is representing as the sexual 
organ of male while bun may refer to the sexual organ of female because of their behavior and the fact that they will have intercourse later on. Therefore, for the sausages, by putting their self into 5 inches deep into some bun is establishing the fact that they will have an interface or sexual intercourse with each other. Then, this scene gives a sense that the characters are having their own desires, implicitly, the characters stated that they will have a sexual intercourse while still standing the jokes as a usual 'Hot Dog'.

Then, the second scene is displayed on 37:13 - 37:18, where the gang of some foods are arrived in the rumoured of 'The Great Beyond'. The scene is focused on the Potato who has a high expectation from the woman who he thought as the God. However, that expectation is only a mirage and cannot be happened at all. He is being peeled by the woman to the point where he cursed her until his last breath. He said, "She is peeling me fucking skin!" while screaming from the suffering and all of his comrades are hearing his speech. Therefore, the analyzed is described below:
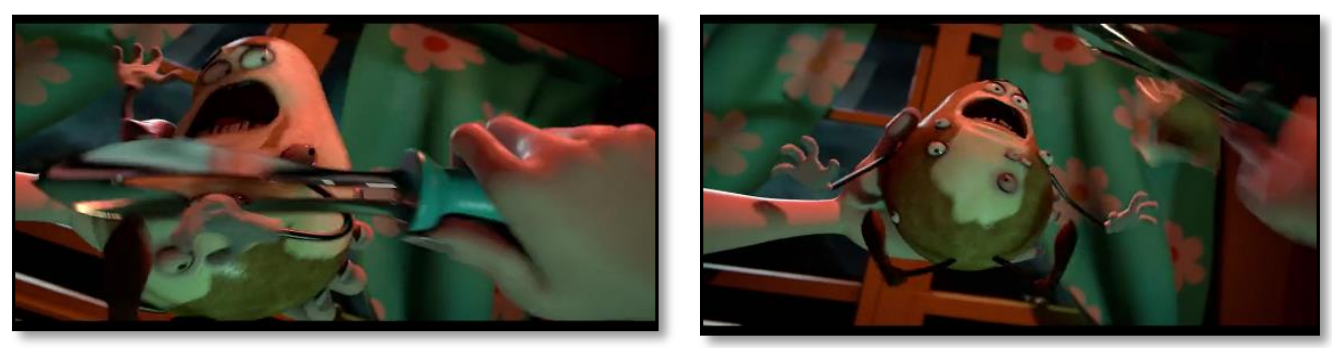

Figure 2 : Second Scene

From Figure 2, it shows the scene where focused on the Potato who is being peeled. The background is dominated by the darkness theme which is possibility representing the sinful and painful value of the scene (Gunther \& Leeuwen, 2006). Then, the scene is used the medium shot frame which showed the body up to the knee of the character, with intends to tell the audiences to not only focused on the potato but also the surrounding area such as the knife and the woman's hand. By the time, the movement of the camera is closing its distance to the Potato, this kind of movement is trying to represent any changes from the Potato like its facial expression, hand movement, etc. Likewise, the position of character is located on the center of the frame, which means that the nucleus of the information is distributed. Therefore, all of the visual elements are cooperating together to support the message from the nucleus (Gunther \& Leeuwen, 2006).

Table 2. Dialogue in The Second Scene

\begin{tabular}{c|c|c|c}
\hline "She & is & Peelling & me fucking skin!" \\
\hline Actor & \multicolumn{2}{c}{ Process:Material } & Goal \\
\hline Subject & $\begin{array}{c}\text { Finite }+ \\
\text { (Present) }\end{array}$ & Predicator & Adjunct \\
\hline \multicolumn{3}{c}{ Mood Block } & Residue \\
\hline Theme & \multicolumn{2}{c}{ Rheme } \\
\hline
\end{tabular}

From Data-2, there are two participants which is she as the actor and me is labeled as the goal of the process, because it is the participant who is concerning by the actor with the action of is peeling which depict physical activities by the actor. Then, it can be interpreted that the Potato is representing himself by used $m e$, as the goal of the process and she to represent the woman who acts as the actor of the process. 
Therefore, this sentence intends to tell that she is doing physical activity which is peeling toward the goal which is represented by me. Then, the other metafunction, based on the interpersonal function, this sentence defines as giving an information to the receiver and categorized as the declarative mood because the subject is preceding the finite. Then, the finite is is a sign of time in relation to the speaker and resembling the event is presently occurring and + symbol is resembling the positive polarity of the speaker. Then, based on the textual function, this sentence is categorized as topical theme because it begins with the subject of she. Therefore, it indicates that the focus of this sentence is to inform about the woman's intention and activity which represented by she.

Therefore, those elements are cooperating to construct some meaning in this scene. Firstly, this scene is giving an information about what is happening toward the Potato which represented by me as the goal while being peeled by she as the actor. The Potato is telling the information to his comrades that she is currently doing physical activity to his skin. Then, the focus of this scene is located in what happened toward the Potato and his speech about she since the nucleus of this scene is distributed to the Potato himself. Furthermore, in the real world, the word of peeling may be in the true concept, however, the fact that all of the things here are alive and had a soul in their self is the main case. It depicted in their mind that the Potato is being skinned while still alive. In fact, animals or even humans can feel the pain by being skinned, moreover it happened while being alive, likewise, it can be argued as the torturing act. The expression of the Potato is also representing the painful which he gets from the peeling action. His scream and expressions are an answer from his suffering. Moreover, the darkness theme is a sign of the painful from the Potato, he did not expect this whole thing will be happened. Therefore, this scene gives a sense that the Potato is having a painful time, being skinned by she while still alive and since everything in this film had its soul, it can be argued that the Potato is also a living creature who can feel pain and suffer. In fact, it will be tortured him if he is a living creature. However, the joke here is about how amusing that non-living creature are suffering due to a peeling action, otherwise, it is also representing of the perspective from the victim, how cruel this action. In the real world, skinning is the same action like peeling, but, if it happened toward a living creature who can feel a pain, they will also give the same reaction like Potato. Ironically, there are so many humans who are also doing the same thing toward other living creatures. This act can be categorized as the concept of killing other creatures without technically killing them. For underage, this scene can be argued as funny action, but, for the adulthood who acknowledged the idea, it can be concluded as the idea of torturing and even to murdered case.

Furthermore, the third scene is displayed on 42:51, Barry is trying to save his life by running away from the she. Whereas, he arrives in the street and meets with many things. Then, he meets with a rubber like creature and stated, "They went inside me... and then splooge!" while screaming. Therefore, the analyzed is described below:

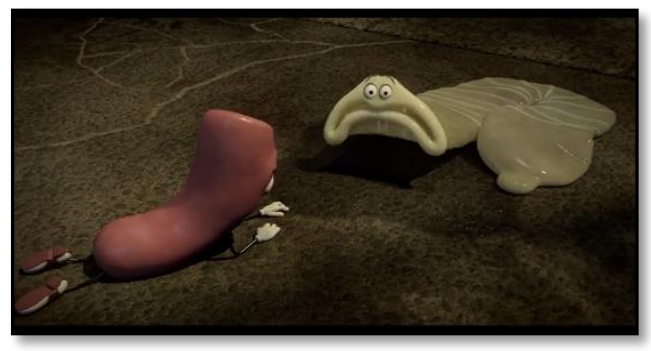

Figure 3 : Third Scene 
From Figure 3, it shows the scene where focused on the meeting of Berry with a rubber creature. The background is dominated by the darkness theme which possibility representing the painful and sinful value of the scene (Gunther \& Leeuwen, 2006). Then, this scene is used medium shot frame which showed the body up to the knee of the character, with intends to tell the audiences to not only focused on the little sausage but also the surrounding area such as the unknown creature. Likewise, the position of characters are located on the left side which indicates the sign of 'already given' or it assumed to be already known by the audience, meanwhile, the right side is the key information which is the audiences need to pay more attention with (Gunther \& Leeuwen, 2006).

Table 3. Dialogue in The Third Scene

\begin{tabular}{c|c|c|c}
\hline Then, & they & went & inside me... \\
\hline Adjunct & Actor & Process:Material & Goal \\
\hline Res- & Subject & $\begin{array}{c}\text { Finite + (Past) } \\
\text { Predicator }\end{array}$ & Complement \\
\hline Textual & Topical & Mood Block & Idue \\
\hline \multicolumn{2}{c}{ Theme } & \multicolumn{2}{c}{ Rheme } \\
\hline
\end{tabular}

Table 4. Dialogue in The Third Scene

\begin{tabular}{c|c}
\hline and then... & splooge! \\
\hline & Process:Material \\
\hline Adjunct & Finite + (Present) Predicator \\
\hline Residue & Mood Block \\
\hline \multicolumn{2}{c}{ Rheme } \\
\hline
\end{tabular}

From Data-3 and Data-4, there are two participants which is they as the actor and inside me is labeled as the goal of the process, because it is the participant who is concerning by the actor with the action of went and splooge which depict physical activities by the actor. Then, it can be interpreted that the speaker is representing itself by used $m e$, as the goal of the actor which represented by they. Therefore, this sentence intends to tell that they were did and are doing physical activity toward $m e$. Then, the other metafunction, based on the interpersonal function, those clauses define as giving an information to the receiver and categorized as the declarative mood because the subject is preceding the finite. Then, the went is considering as a sign of time of the event which is happened in the past, meanwhile, the splooge is considering as a sign of time which is presently occurring. Both of those are used + symbol which is resembling the positive polarity of the speaker. Then, based on the textual function, this is categorized as the textual theme because it begins with the conjunction which connects it to the previous message. Therefore, it indicates that the focus of this sentence is to inform about actor's (they) activity toward me.

Therefore, those elements are cooperating to construct some meaning in this scene. Firstly, this scene is giving an information about what was happened toward the Rubber which represented by me as the goal while they as the actor. The Rubber is telling the information to Berry that they already did physical activity toward him which represented by went. Then, the focus of this scene is located in what happened 
toward the Rubber and his speech about they. Furthermore, based on his speech, they can refer to the humans and went inside means that they were putted something inside him. In fact, either in the real world or in the film, the once who can use rubber is only human, it can be assumed that they is a human being. Therefore, the splooge represents the presently occurring event base and also a slang word for cum. Surely, this term is rarely used in daily life but it has a same meaning with cumming while man already in his climax. Therefore, it can be argued that they were used the Rubber while they had intercourse and then cumming into him. They here is a plural term which means more than one person who used him before and it has a possibility that more than one person who splooge inside him. Therefore, it can be assumed that they have an orgy and doing it outside of the building since Berry founds him in the middle of street. It has a possibility that after they already used it, they throw it away in the street, it can be from the car or the nearby park or other places as well, with filled with the sperm as the sign of intercourse activity. Then, the darkness theme is representing the suffering from the Rubber, in fact, before using the Rubber they will stretching it out in order to putting it inside and used it as they pleasure.

\section{CONCLUSION}

This research on Sausage Party Movie is applying multimodality approach and discovers 3 scenes which contain some adult jokes inside. The first scene indicates with the idea of intercourse between sausage and bun, likewise how male and female doing copulation. Then the second scene indicates with the idea of how painful to be skinned while still alive, it relates with the idea of torturing someone. Then, the third scene also indicates with the idea of intercourse, however, this scene is for humans who used the Rubber in their intercourse activity which torturing the Rubber. Therefore, those adult jokes are being displayed implicitly to entertain adulthood who understood the meaning or the underage communities who think it as a normal joke. This animated movie becomes one of the works which displayed adult jokes to attract both of the adulthood and underage communities.

On the other hand, this study undoubtedly has its limitation and still has much room for improvement. This research does not analyze the adult jokes from another perspective or approach, which might add more enlightenment in analyzing this topic.

\section{REFERENCES}

Bo, X. (2018). Multimodal Discourse Analysis of the Movie Argo. English Language Teaching, 11(4), 132. https://doi.org/10.5539/elt.v11n4p132

Butt, D., \& Fahey, R. (2000). Using Functional Grammar: An Explorer's Guide (Second). Sydney: Macquarie University.

Chasanah, N. (2020). Revealing the Hidden Message from Cigarette Advertisement Multimodal Discourse Analysis. Litera Kultura, 09(02), 196-205.

Chelsie, A. (2013). The Rise of Humor: Hollywood Increases Adult Centered Humor in Animated Children's Films (Brigham Young University). Retrieved from https://scholarsarchive.byu.edu/etd\%0Ahttps://scholarsarchive.byu.edu/cgi/vie wcontent.cgi article $=4723 \&$ context $=$ etd

Chivanec, J., \& Ermida, I. (2012). Language and Humour in the Media. United Kingdom: Cambridge Scholars Publishing. 
Creswell, J. W. (2014). Research Design: Qualitative, Quantitative, and Mixed Methods Approaches (4th ed.). United States Of America: Sage Publications, Inc.

Gunther, K., \& Leeuwen, T. Van. (2006). Reading Images: The Grammar of Visual Design (Second). USA: Routledge.

Halliday, M. A. K., \& Hasan, R. (1989). Language, Context, and Text Aspects of Language in a Social-Semiotic Perspective (F. Crisyie, Ed.). Oxford: Oxford University Press.

Heljakka, K. (2016). Fifty shades of toys: Notions of play and things for play in Fifty Shades of Grey Canon. Cult Media, (8). Retrieved from https://www.researchgate.net/profile/Katriina_Heljakka/publication/303015740 _Fifty_Shades_of_Toys_Notions_of_Play_and_Things_for_Play_in_the_Fifty_ Shades_of_Grey_Canon/links/5735854208ae9ace8409f10f/Fifty-Shades-ofToys-Notions-of-Play-and-Things-for-Play

Liu, S. (2019). A Multimodal Discourse Analysis of the Interactive Meaning in Public Service Advertisement. Journal of Advances In Linguistics, 10, 1523-1534. Retrieved from https://rajpub.com/index.php/jal

Nita, H. (2015). A Pragmatic Analysis of Humor Expressed by Aladeen In The Dictator Movie. State University of Yogyakarta.

Nugraha, I. S., \& Mahdi, S. (2020). Transitivity System on Building Character of Mr. Summers in the Lottery By Shirley Jackson. Celtic: A Journal of Culture, English Language Teaching, Literature and Linguistics, 7(1), 35. https://doi.org/10.22219/celtic.v7i1.11980

O'Halloran, K. L. (2004). Multimodal Discourse Analysis Systemic-Functional Perspectives. London - New York: Continuum.

O’Halloran, K. L. (2008). Systemic Functional-Multimodal Discourse Analysis (SFMDA): Constructing Ideational Meaning Using Language and Visual Imagery. Visual Communication, 7(4), 443-475. https://doi.org/10.1177/1470357208096210

Ross, A. (2005). The Language of Humour. https://doi.org/10.4324/9780203984567

S. Knox, J. (2012). Multimodality and Systemic Functional Analysis. The Encyclopedia of Applied Linguistics. https://doi.org/10.1002/9781405198431.wbeal0836

Savitri, M. T., \& Rosa, R. N. (2019). A Study of Multimodal Analysis In Smartphone Advertisement. E-Journal of English Language \& Literature, 8(3). Retrieved from http://ejournal.unp.ac.id/index.php/jell

Tsakona, V. (2009). Language and Image Interaction in Cartoons: Towards a Multimodal Theory of Humor. Journal of Pragmatics, 41(6), 1171-1188. https://doi.org/10.1016/j.pragma.2008.12.003

Wahyuni, E. (2014). Exposing Literature into Language Teaching and Learning. Celtic: A Journal of Culture, English Language Teaching, Literature, \& Linguistics, 2(2), 63-74. https://doi.org/10.22219/celtic.v1i2.4668 